\title{
Visualisation of elastic numerical modelling results for effective mine planning and design
}

\author{
K. du Plooy SRK Consulting, Australia \\ F. Basson Newmont Asia Pacific, Australia
}

\section{Abstract}

One of the challenges that geotechnical engineers are faced with today is how to present numerical modelling results in an effective manner.

The elastic BEM software, Map3D-SV, has been the trustworthy stress modelling software of choice to operational and consulting geotechnical engineers for many years. Through a process of back analysis, elastic modelling stress results can be effectively used on mines where rock stresses contribute to observed failures. Conceptual Map3D models also provide useful insights into the likely stress distribution around underground excavations that can be used to direct mine planning from conceptual study through to the operational phase.

Map3D results are typically displayed as flat contoured surfaces on grids placed at the area of interest. This has proved to be largely ineffective when the aim is to capture the volumetric implications in a three dimensional mining environment. Other visualisation techniques such as iso-surfaces and colour mapping of results on excavation surfaces are far superior, but not yet supported in the Map3D-SV.

This paper discusses visualisation techniques and demonstrates potential application areas for each:

1. Iso-surfaces from modelling results:

a. crude iso-surfaces in Map3D

b. detailed iso-surfaces using other software packages (Voxler, 2011; Leapfrog, 1997-2011; GoCAD, 2011).

2. Colour mapping of surfaces from modelling results:

a. colour mapping surfaces from a cloud of result points (Leapfrog, 1997-2011; or GoCAD, 2011)

b. mapping of spatially selected results to excavation surfaces (specific process in REM3D, 2011).

Excavation surfaces can be colour mapped according to results from points generated at a predetermined density, and a fixed distance from excavation surfaces for detail.

The visualisation techniques discussed in this paper have been found useful in both feasibility studies and operational investigations. They are superior to flat contours in many instances, but especially where a global understanding of the stress impact, or the selected design criterion, is required. Other benefits that flow from these techniques are:

- Iso-surface triangulations can be exported and provided to planning engineers for design guidance.

- Colour mapped results on excavation surfaces can be easily related to observed behaviour in underground openings.

- Two dimensional numerical modelling data can be viewed in combination with three dimensional data. 


\section{Introduction}

The saying 'a picture is worth a thousand words' refers to the concept that a complex idea can be conveyed with just a single still image. It also aptly characterises one of the main goals of visualisation, namely making it possible to absorb large amounts of data quickly. This saying is widely accredited to the advertising industry and was quoted in the early 1900s already.

Geotechnical engineers are often faced with the challenge of presenting the inherent complexities within numerical models in a way that will allow quick and informed decision making by all levels of mining individuals.

This paper discusses a few innovative methods available for presenting different types of geotechnical data to provide a single model to that captures all available data. Most of the methods discussed in this paper have already been widely used in other scientific fields and therefore does not necessarily present new technology. It merely illustrates what is possible with a little bit of creativity. The aim with this paper is to illustrate how data from the more commonly used modelling packages, such as Map3D (Mine Modelling, 2012) and the Rocscience (2012) suite of software can be integrated with mining excavation wireframes and geological information to create a fully three dimensional image of all available information.

\section{Data presentation}

When faced with the task of presenting complex data, it is worth thinking about the effect of subtle changes in data presentation on results interpretation. Even a minor issue, such as the aspect ratio of a two-dimensional graph, could be an important factor when visually decoding information. For example, Figure 2 shows the number of sunspots per year in two panels, with the aspect ratio of the top panel more exaggerated than the bottom panel. Exaggeration is normally assumed as beneficial when inspecting cyclical data, but masks important rate of change information in this particular case. Although the 11 year cycles are evident in both panels, the top panel fails to reveal that the cycles rise more rapidly than they fall. Even more information is visually obvious from the bottom panel; the faster rise than fall is more pronounced for the cycles with high peaks, less pronounced for the medium peaks, and disappears for the lowest peaks (Cleveland, 1994).
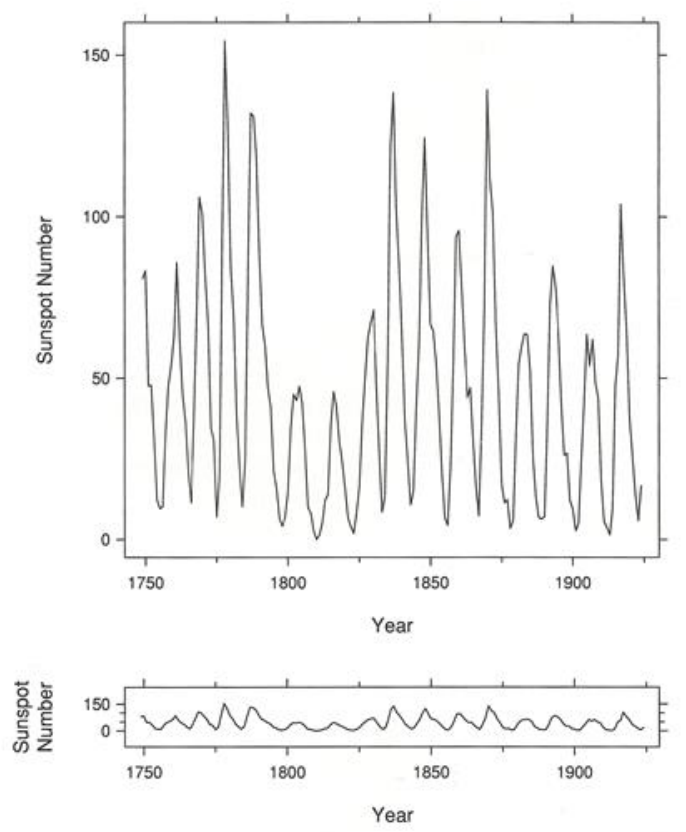

Figure 1 Example of impact of aspect ratio on data presentation (Cleveland, 1994)

If important information in a two-dimensional line graph can be masked by something as simple as an unfortunate selection of the aspect ratio, the visualisation techniques and colour schemes selected in 
complex three dimensional scenarios could be even more pronounced. A three-dimensional picture combining information from many sources is always superior to loose data fragments, but the presentation should still be carefully selected. Visualisation variables such as colour schemes, transparency and isosurface values should be carefully selected to highlight the important variables for the scenario considered.

\section{Visualising geotechnical data}

When making a decision on how geotechnical data is presented, it is very important to keep the audience in mind.

- Geotechnical engineers will be interested in the technical detail and understanding the scientific and engineering base of the presented data.

- Mining engineers on the other hand will want to know how the data will influence decisions related to mining of a specific orebody.

- From a corporate perspective, mine management will want to develop a quick understanding of potential risks that the data may highlight or the potential for expansion of mining activities in areas where a lower geotechnical risk exists.

- From a legislative point of view, mine scale data presentation in a fully three dimensional environment assists in showing due diligence in that all available data may be considered before making any decision that could affect the health and safety of workers.

The aim of visualisation should always be to explain technical concepts in the simplest manner possible.

\section{1 Data types}

Most geotechnical problems are encapsulated by all or most of the data types in Table 1. All of these data types can be described in terms of its spatial location (i.e. X-, Y- and Z-coordinates) and assigned a numerical value that can either be presented in a $2 \mathrm{D}$ graph or manipulated with advanced software techniques to construct three dimensional models.

Table 1 Geotechnical data types

\begin{tabular}{cccc}
\hline $\begin{array}{c}\text { Rock Mass } \\
\text { Classification Data }\end{array}$ & $\begin{array}{c}\text { Structural } \\
\text { Orientation Data }\end{array}$ & Seismic Data & $\begin{array}{c}\text { Numerical Modelling } \\
\text { Results }\end{array}$ \\
\hline $\begin{array}{c}\text { Barton's Q } \\
\text { classification }\end{array}$ & Drill holes & Local magnitude & $\begin{array}{c}\text { 3D models, e.g. Map3D, } \\
\text { FLAC3D, 3DEC }\end{array}$ \\
$\begin{array}{c}\text { Laubschers MRMR } \\
\text { Bieniawski RMR }\end{array}$ & Face mapping & Peak particle velocity & 2D models, e.g. Phase ${ }^{2}$ \\
RQD & $\begin{array}{c}\text { Geology structural } \\
\text { interpretation }\end{array}$ & Apparent volume & \\
GSI (Hoek) & & Energy index & \\
\hline
\end{tabular}

Other data types that could potentially be incorporated into descriptive models include:

- photogrammetry, bitmap images or photographs

- mining wireframes

- geological wireframes

- ore reserve data. 


\section{$4 \quad$ Where did it all begin?}

Target Gold Mine in South Africa is a complex, multiple-stope mining environment utilising massive mining methods at $2300 \mathrm{~m}$ below surface. Conventional tabular stoping is used to de-stress the rock to enable massive open stoping operations in artificially created "shallow conditions". Cemented backfill is then used to enable high extraction ratios with multiple stacked open stopes. Keeping track of all possible high-risk scenarios without three dimensional mine design software is a daunting task in such an environment.

In 2000 the mine planning software of choice was Datamine Studio 2. In this version of the software all design work is done in a two dimensional section view, with a very basic three dimensional visualiser. The visualiser could only visualise a fixed scene; and measurements, rotation point changes, and design changes could not be done in this viewer.

This lead to the development of REM3D (Basson, 2009) which provided a powerful platform to display mining plans, geotechnical data and numerical modelling results. Map3D results are typically displayed as flat contoured surfaces on grids placed at the area of interest. This has proved to be largely ineffective when the aim is to capture the volumetric implications in a three dimensional mining environment. Other visualisation techniques such as iso-surfaces and colour mapping of results on excavation surfaces are far superior, but not yet supported in the Map3D-SV. During the development of REM3D, the added flexibility was soon realised in more than visualising mine plans. All forms of information were combined and new visualisation methods explored during 2001 as shown in Figure 2 (Basson and Schwab, 2001).

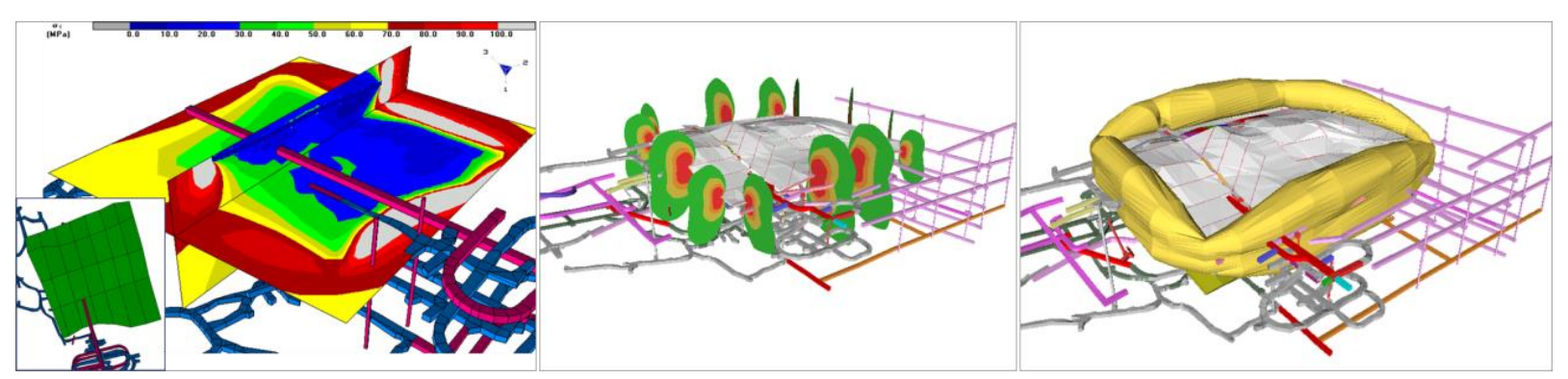

Figure 2 The evolution of data representation (Basson and Schwab, 2001)

\section{$5 \quad$ Modern visualisation methods}

Various software packages are available for data visualisation in three dimensions. The authors and others have used the following software packages successfully to construct three dimensional geotechnical models:

- Leapfrog (1997-2011).

- $\operatorname{Voxler}(2011)$.

- REM3D (2011).

- GoCad (2011).

Some of these software packages allow rapid construction of geotechnical wireframes directly from scattered data points without the need for manual digitisation. These are the commercial software packages such as Voxler (2011), Leapfrog (1997-2011) and GoCad (2011). The freeware, REM3D (2011) requires some degree of creativity and external manipulation of data but provides a powerful and cost effective visualisation tool.

Leapfrog allows the construction of geotechnical models using 3D interpolation technology. This method of geological/geotechnical modelling is termed implicit modelling. Implicit modelling, in contrast to traditional explicit modelling, does not require time-consuming manual digitisation. This effectively compresses the time required for modelling from days to hours. Users not familiar with Leapfrog can normally learn to operate the software and generate models within a few hours. 


\section{1 Iso-surfaces}

An iso-surface is a three dimensional analogue of an isoline. It is a surface that represents points of a constant value (e.g. pressure, temperature, velocity, density, stress, etc.) within a volume. Iso-surfaces tend to be a popular form of visualisation for volumetric datasets, since they can be rendered by simple polygonal models which can be drawn on the screen very quickly.

In medical imaging, iso-surfaces may be used to represent regions of a particular density in a three-dimensional CT scan, allowing the visualisation of internal organs, bones, or other structures. Using the same technique, data from individual "scans" (computational grids) in Map3D can be used to construct iso-surfaces of a chosen parameter to evaluate a particular mining layout from a geotechnical point of view.

Figure 3 shows an example of how an iso-surface may be used to identify areas of interaction between closely spaced drives under high stress conditions. In this instance, the iso-surface model also assists in gaining a better understanding of the location of observed stress induced rock mass damage highlighted in red.

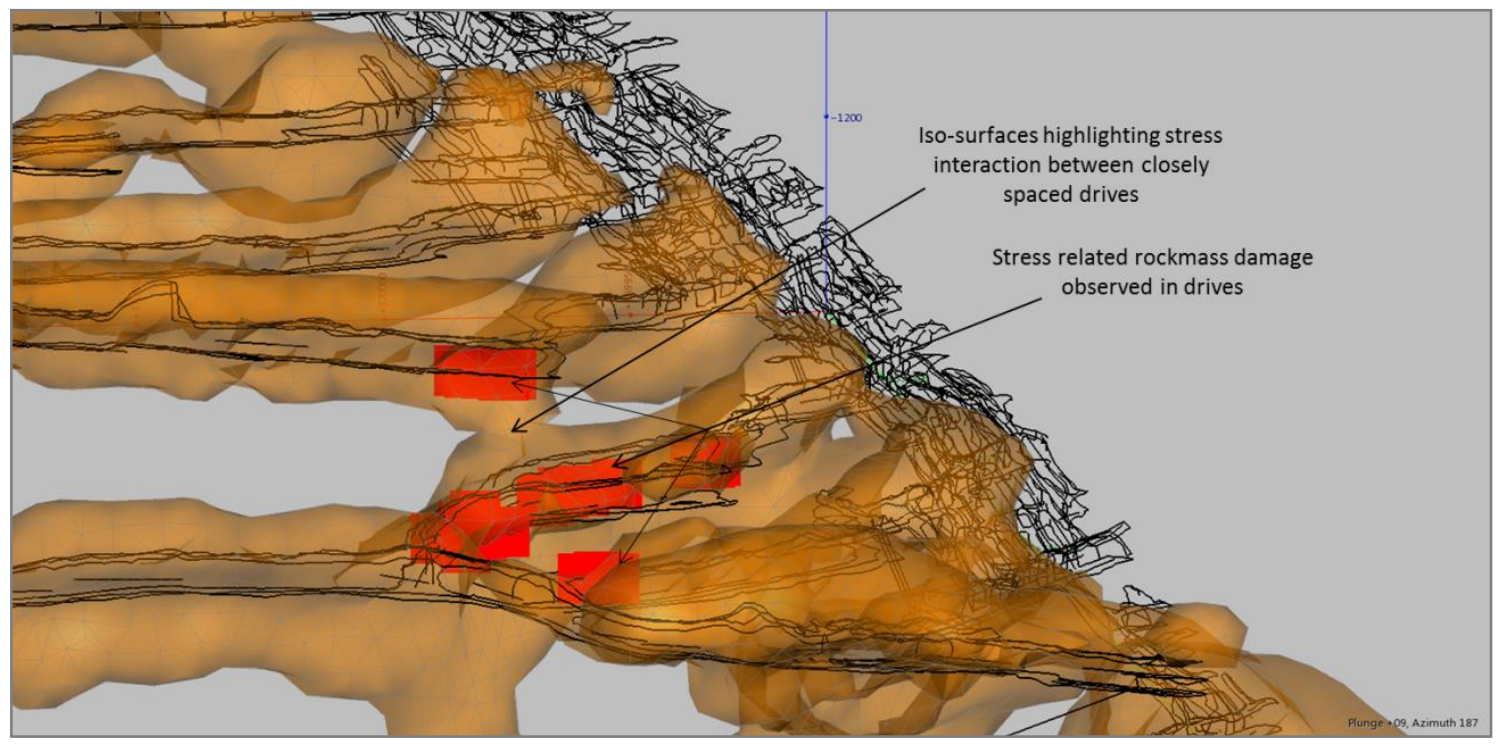

Figure 3 Iso-surface model

Mining engineers often require guidance on the placement of infrastructure development. Figure 4 shows a wireframe of stress iso-surfaces superimposed on a proposed development layout. Although the iso-surfaces represent abutments generated by stopes, it is the impact of these abutments on mine development that is important in this instance. At conceptual level and feasibility level mine design, such wireframes allow an effective method to scrutinise development layouts and also provide guidance to mine planning engineers on areas to avoid with critical infrastructure development. At an operational level, it may even be possible to calibrate the iso-surface model against actual underground observations. Take into account that this paper does not make any recommendation on specific design criteria to be used; it merely shows the potential ways of visualising data. 


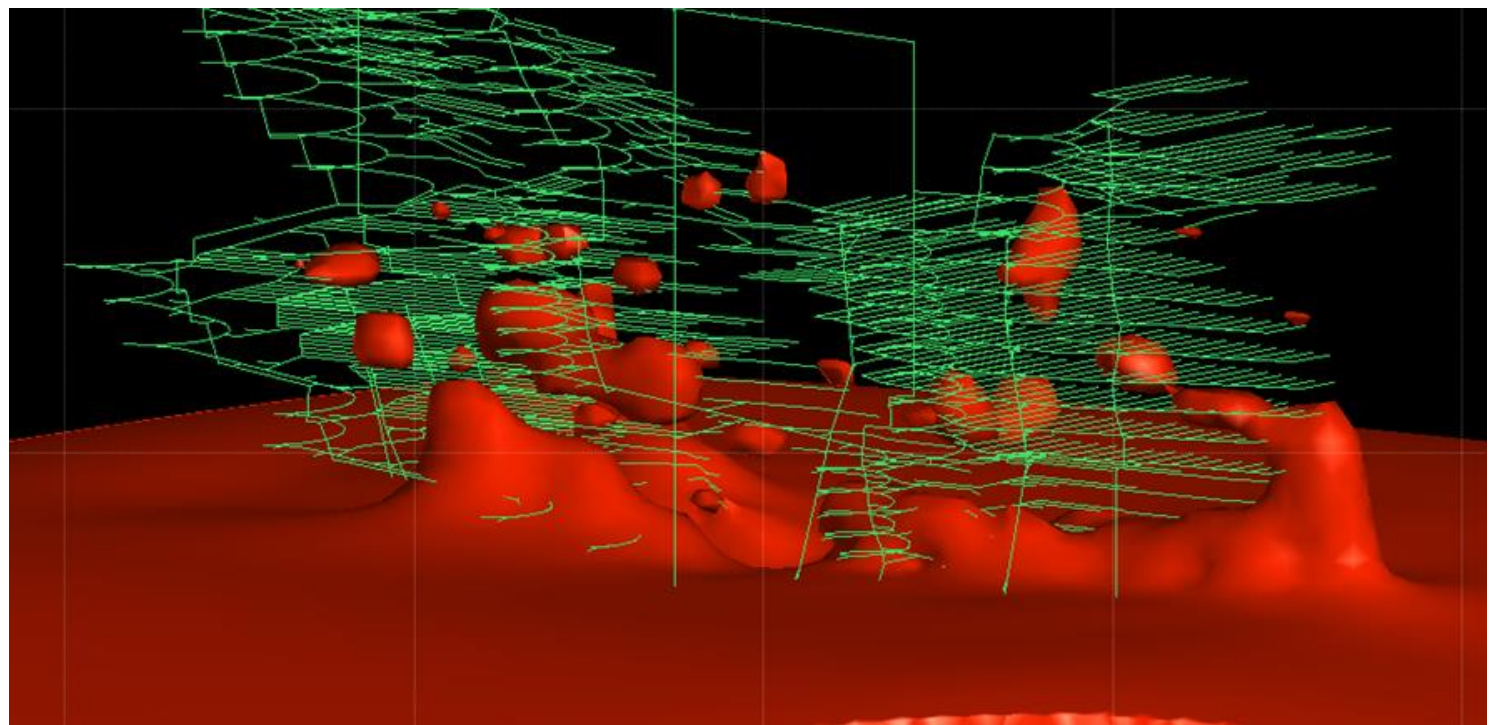

Figure 4 Visualisation of Map3D modelling results

\section{2 Surface colour mapping}

The process of colour mapping entails displaying data points closest to a wireframe or polygon on the polygon as a colour.

\subsubsection{Global picture (Leapfrog)}

On a mine scale, colour mapping of stress data is particularly useful to identify areas that may be at risk of experiencing stress related damage. This provides an opportunity to manage potential hazards through either changing mining sequences or by making additional provision for ground support. Mine scale colour mapping also provides a high level overview of the relative hazard profile of access development as shown in Figure 5. Warmer colours will indicate areas of higher risk while cooler colours will indicate areas of lower risk.

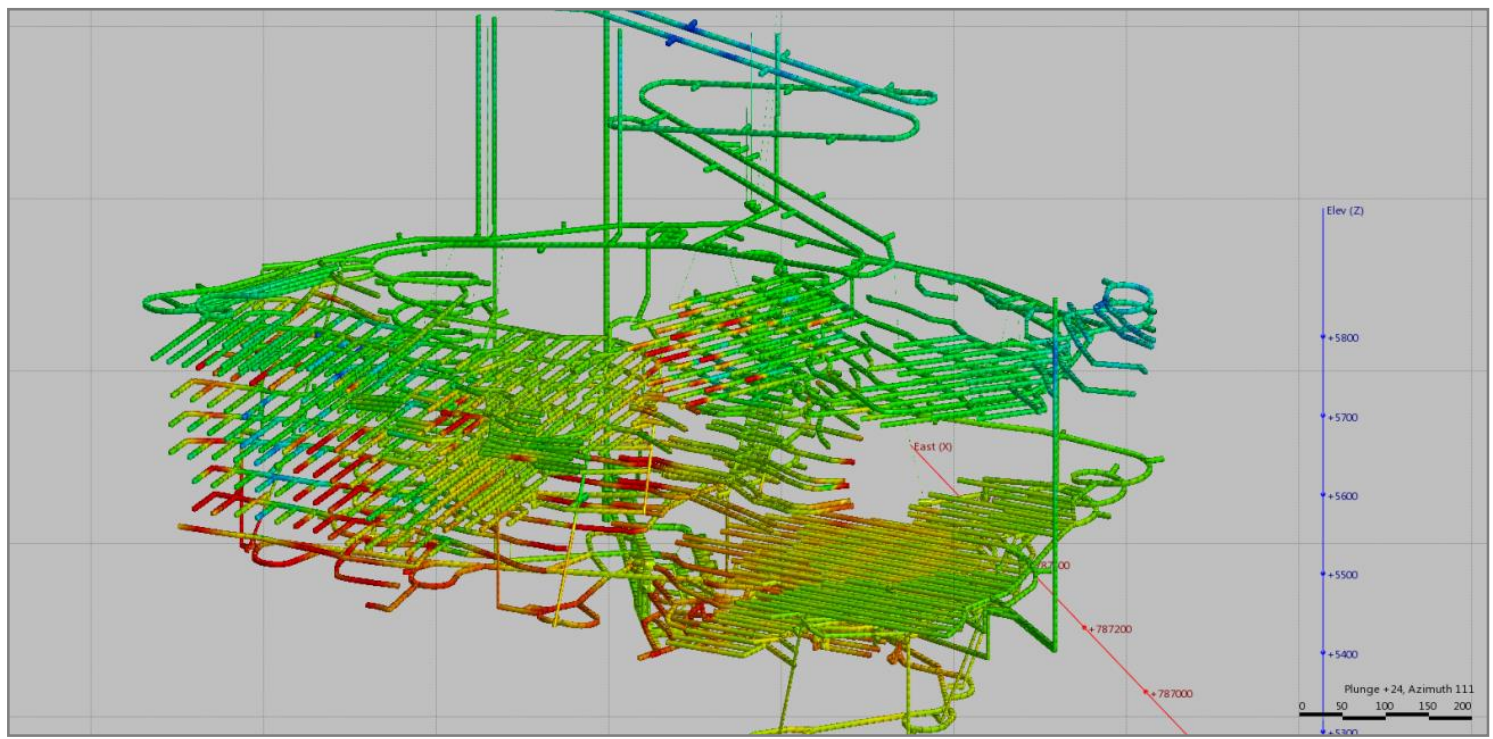

Figure 5 Mine scale colour mapping

\subsection{Point data (REM3D)}

Based on the assumption that a relation exists between the amount of overstressing in a numerical model and the amount of damage observed in the rock mass, elastic modelling results have been used to estimate 
anticipated damage in development. The approach is outlined in previous papers (Basson, 2009; Graf and Basson, 2010) and consists of a few steps:

1. Record observed underground damage.

2. Construct and run Map3D models of the observation areas.

3. Develop design criteria from the near-field stresses and observations.

4. Colour map the development according to the established design criteria.

Figure 6 shows an example of using colour mapping to present point data, such as design criteria calculated specifically for the area of direct influence around an excavation. In the example, dark red indicates areas where the design criteria are exceeded and stress damage may be possible.

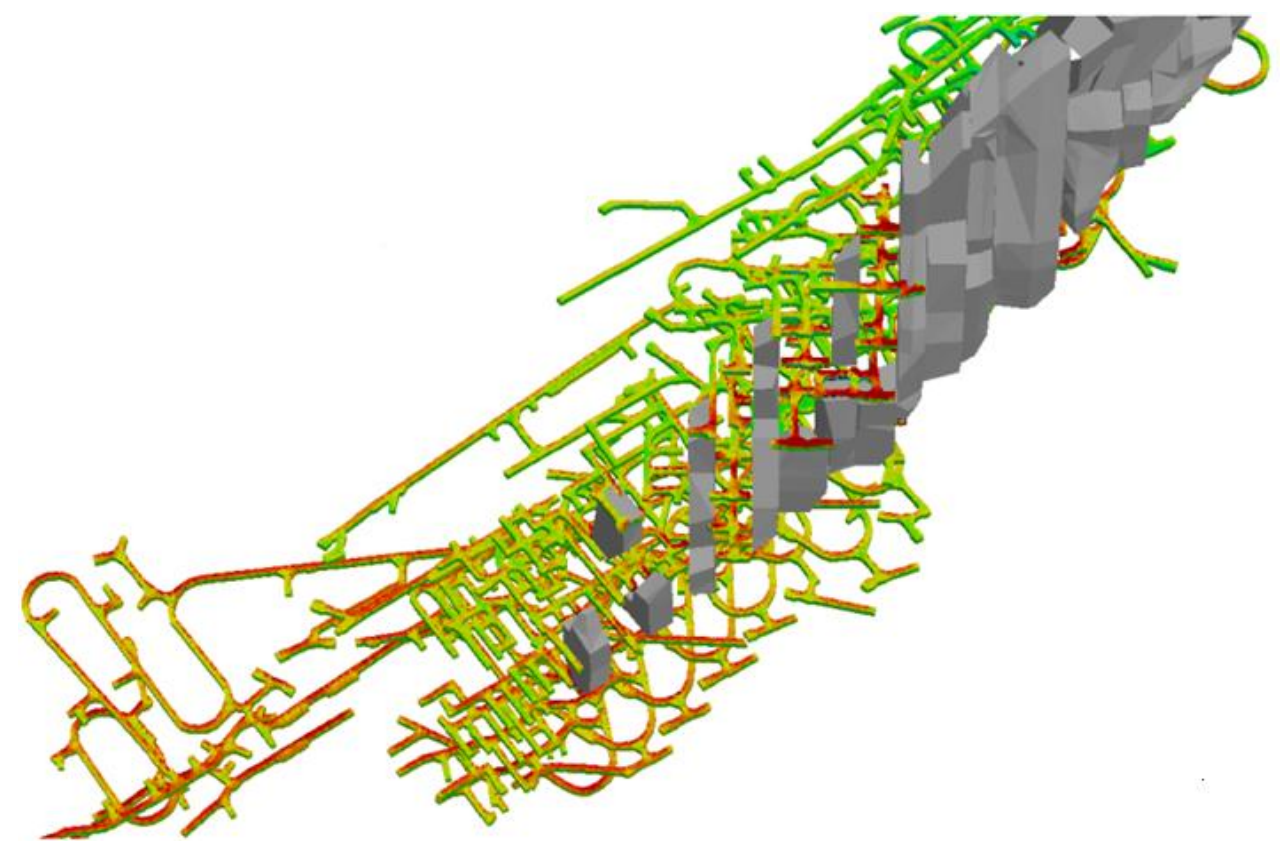

Figure 6 Design criteria mapped onto existing development (www. basrock.com)

\section{$6 \quad$ Bitmaps and photographs}

Sometimes engineers have to use any available data to make an assessment of the prevailing or expected geotechnical conditions. This may sometimes include a combination of three dimensional data and twodimensional sections from modelling packages such as Rocscience's Slide ${ }^{\circledR}$ (2012) as shown in Figure 7. In this instance a Slide model section is displayed along with iso-surfaces representing stoping stress abutments (De Bruyn et al., 2009). 


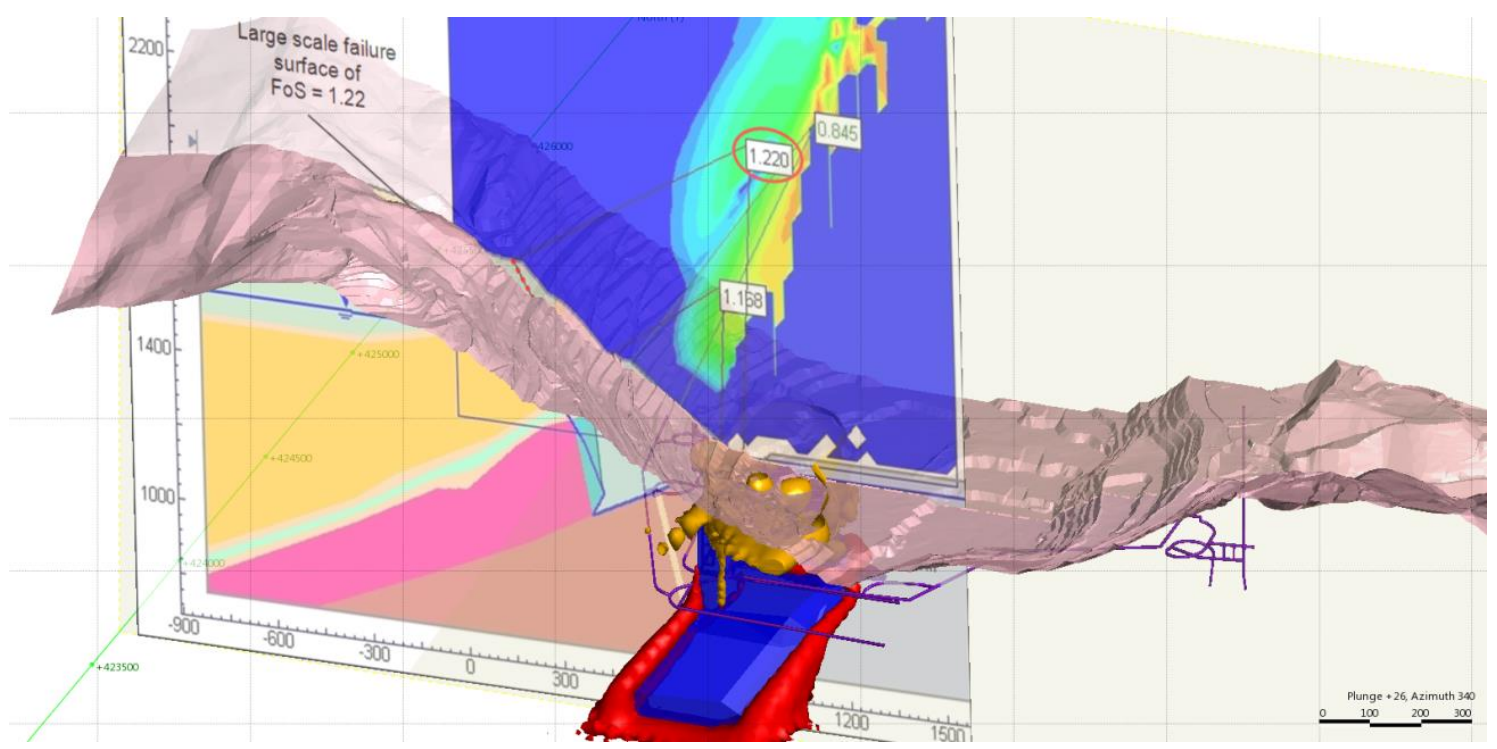

Figure 7 Combination of 2D and 3D modelling results

\section{Data requirements}

In order to visualise data in a sensible manner, the following should be kept in mind:

- Sufficient data should be available to allow reasonable interpolation between points. If data points are spaced too far apart, the interpolation process may result in large errors and the benefits of presenting numerical data as e.g. iso-surfaces will be lost.

- Data imported into visualisation software should be from a reliable source and should be where possible be calibrated against actual observations.

\section{Conclusions}

Much progress has been made in the ability to visualise data from different sources in three dimensions over the last decade. When development of REM3D started around 2001, software with similar capabilities was not available, but many commercial packages exist today that could be used for similar tasks.

Visualisation techniques will become more powerful and common in all fields of engineering. This new trend can be resisted or embraced, but the authors personally experienced the improved productivity and decision making ability resulting from embracing these technologies.

\section{Acknow ledgements}

The authors thank Newmont Mining, Randgold Resources and SRK Consulting for allowing them the opportunity to write this paper and present some of their exclusive data.

\section{References}

Basson, F.R.P. and Schwab, N.M. (2001) Overcoming Limitations of Current Numerical Modelling Software for Complex, Three Dimensional Mining Geometries, Association of Mine Managers of South Africa.

Basson, F.R.P. (2009) REM3D notes available from the REM3D-page at http://www.basrock.com/.

Cleveland, W.S. (1994) The Elements of Graphing Data, Hobart Press, Summit, New Jersey, USA.

De Bruyn, I., Mylvaganum, J., du Plooy, K., Price, J., Baczynski, N. and Coulthard, M.A. (2009) Numerical analyses for evaluation of pit wall stability and stresses resulting from proposed underground mining excavations beneath the Ok Tedi open pit, Papua New Guinea, International Symposium on Slope Stability in Open Pit Mining and Civil Engineering 2009 (Slope Stability 2009), Santiago, Chile, November 09-11 2009.

GoCAD (2011) Commercial software from Mira Geoscience, viewed 29 January 2012, http://www.mirageoscience.com. 
Graf, C.C. and Basson, F.R.P. (2010) Managing Stress and Ground Condition Changes with Increasing Depth at Callie Underground Mine, in Proceedings Second Australasian Ground Control in Mining Conference, P. Hagan and S. Saydam (eds), 23-24 November 2010, Sydney, Australia, pp. 119-125.

Leapfrog (1997-2011) ARANZ Geo Ltd., viewed 29 January 2012, http://www.leapfrog3d.com.

Mine Modelling, Map3D, viewed 29 January 2012, http://www.map3d.com.

REM3D (2011) Freeware software, viewed 29 January 2012, http://www.basrock.com/.

Rocscience, Slide ${ }^{\circledR}$, viewed 29 January 2012, http://www.rocsience.com.

Voxler (2011) Commercial software from Golden Software, viewed 29 January 2012, http://www.goldensoftware.com/. 
